\title{
Regression with ARIMA Error Model for Government Expenditure in Sri Lanka
}

\author{
Kalana N. Alupotha \\ Actual Growth Consultancy (Pvt) Ltd, 431/1, “Indunil”, Gohagoda, Katugastota, Sri Lanka.
}

How to cite this paper: Kalana N. Alupotha. (2021) Regression with ARIMA Error Model for Government Expenditure in Sri Lanka. Journal of Applied Mathematics and Computation, 5(3), 165-170.

DOI: $10.26855 /$ jamc.2021.09.003

Received: July 21, 2021

Accepted: August 15, 2021

Published: August 24, 2021

*Corresponding author: Kalana N. Alupotha, Actual Growth Consultancy (Pvt) Ltd, 431/1, “Indunil”, Gohagoda, Katugastota, Sri Lanka.

Email: alupotha@gmail.com

\begin{abstract}
The economic growth of a country is directly influenced by fiscal policy variables such as government expenditure. Abnormal government expenditure is an important macroeconomic problem faced by the countries at different points of time. In Sri Lanka, for last three decades, unusual government expenditure has become a one of the severe macroeconomic problems and moreover it has led to persistent budgetary deficit as well. Hence, analyzing government expenditure in Sri Lanka will give us a clear deportment of the economy and it has become crucial as abnormal government expenditure can be vulnerable. In this paper, regression with ARIMA error model for government expenditure in Sri Lanka has been derived by analyzing an annual authentic data set from 1981 to 2016 and the model has been verified using standard statistical techniques. Finally, in order to illustrate the precision of the model, actual and forecasted values have been depicted in one graph.
\end{abstract}

\section{Keywords}

Government Expenditure, Regression, ARIMA Error Model

\section{Introduction}

The government expenditure includes total public spending on purchase of goods and services, payment of wages and salaries to public servants, public investment, infrastructure development, transfer payments (e.g. pensions, subsidies, unemployment allowances, grant and aid, payment of interest, and amortization of loans) [1]. Abnormal government expenditure is an important macroeconomic problem faced by the countries at different points of time. In Sri Lanka, for last three decades, unusual government expenditure has become a one of the severe macroeconomic problems and moreover it has led to persistent budgetary deficit as well. Budgetary deficit occurs when the government expenditure rises much faster than the revenue. The government must have some distinct strategies that can be applied to mitigate the adverse effect of budgetary deficit. Those are cutting down the public expenditure, increasing the tax rates and borrowing money as debt [1]. However, these options have serious adverse effects on the economy as a whole. Considerable level of cutting down government expenditure leads to political instability of the government as size and the composition of government expenditure is a matter of goodwill of the government. Borrowed money as debt can be recovered by enhancing tax rates. However, increased tax rates and persistent expansion of money supply escalate price levels of the economy [1]. In Sri Lanka, government expenditure has increased sharply in relation to other countries in Asia. It is obvious that abnormal government expenditure takes place in Sri Lanka due to following major reasons.

\section{1 prolonged ethnic crisis:}

For last three decades, unnecessary government expenditure due to prolonged war was one of the severe and inextricable problems in Sri Lanka and always government had to change their monitory policies according to fluctuations of the war expenditure. 


\section{2 global financial crisis especially in 2nd half of 2009:}

The Financial crisis in 2008-2009 is considered by many economists to be the worse financial crisis since the great depression in 1930s. During the period of economic recession people normally suffer with high unemployment, low disposable income together with unbearable inflationary conditions [2, 3]. Magnitude of global financial crisis was much larger than the recession in 2001. Deterioration of currency values and significant drop of gross domestic products were complicated problems faced by major economies in the world. Hence, during this period government of Sri Lanka had to disburse more for their imports and this led to enhancement of government expenditure.

\section{3 low level of tax rates:}

Sri Lanka is being considered as a country having low tax rates. Sri Lanka, as a democratic country, lot of compulsory consumptions such as education and health provide free of charge and plenty of services are being provided with very low tax rates. Hence, alternatively government has to settle all spending which leads to persistent government expenditure.

\section{4 salary revisions of government employees in critical times:}

Wages in Sri Lanka can be analyzed under two main categories. Those are public sector and private sector. The public sector consists of government and semi-government sectors while the private sector comprises formal and informal sectors. Public sector wages and salaries are fixed by the state and revisions to these wages are made from time to time. For instance, in 2005, public sector employees were able to enjoy significant wage increases as a result of the implementation of the second salary revision of 2004 effective from 01 December 2004. In December 2004, 40\% of the basic salary was increased subject to a minimum of Rs. 3,250 per month and a maximum of Rs. 9,000 per month, plus allowances [4]. Moreover, one of the extraordinary salary increments took place in first half of 2016 which was Rs. 10,000 per month. Owing to all salary revisions come under government expenditure, persistent and vulnerable government expenditure can occur.

Hence, analyzing government expenditure in Sri Lanka will give us a clear deportment of the Sri Lankan economy as economic growth of a country is directly influenced by fiscal policy variables such as government expenditure and abnormal government expenditure can be vulnerable.

\section{Methods}

In order to fit a time series model for government expenditure, the statistical software MINITAB was used. Since vital fluctuations of government expenditure take place from 1981 to 2016, an annual authentic data set from 1981 to 2016 was taken from annual report of central bank of Sri Lanka. Trend analysis was done for four model types. Those are linear, quadratic, exponential growth and S-curve (Pearl-Reed logistic). In order to select an appropriate model for the trend, Mean Absolute Percentage Error (MAPE) was utilized. Mean absolute percentage error is defined as [5] MAPE $=\frac{100}{n} \sum_{k=1}^{n}\left|\frac{y_{k}-f_{k}}{y_{k}}\right|$; where $y_{\mathrm{k}}=\mathrm{k}^{\text {th }}$ observed value, $f_{\mathrm{k}}=\mathrm{k}^{\text {th }}$ fitted value using trend model and $n=$ number of observations. Here, $y_{k}-f_{k}\left(=e_{k}\right)$ indicates the error component. Therefore, it is obvious that a model contains minimum error leads to a best model. Consequently, a trend model which consists of least MAPE value can be taken as the best selection criteria [5]. In this analysis, S-curve was selected as it has the minimum MAPE value among others. In order to enhance the accuracy of the trend/regression model, residual analysis has to be done. It is well known that, residuals of a regression model should fulfill some specific conditions [6]. Those are residuals have constant variation, residuals should be normally distributed and residuals should be uncorrelated/random. Since residuals of our S-curve trend model do not follow all aforementioned conditions simultaneously, an ARIMA model was fitted for residuals of the trend model. In order to fit an ARIMA model for residuals, Log transformation for the data set of residuals was applied as it is one of the typical remedies to handle a non-stationary data set and there after autocorrelation function (ACF) and partial autocorrelation function (PACF) were used as useful tools to derive the ARIMA(p, d, q) model [5].In general, including back shift operator $(B)$, an $\operatorname{ARIMA}(p, d, q)$ model mathematically can be written as [5]

$\left(1-\sum_{i=1}^{p} \varphi_{i} B^{i}\right)(1-B)^{d} x_{t}=c+\left(1-\sum_{j=1}^{q} \theta_{j} B^{j}\right) \epsilon_{t}$; where $c$ is a constant, $p, d$ and $q$ are integers greater than or equal to zero and refer to the order of the autoregressive, integrated, and moving average parts of the model respectively and $d$ is an integer which controls the level of differencing. Finally, regression with ARIMA error model was derived for government expenditure in Sri Lanka.

\section{Results}

In order select the appropriate model for the trend, all MAPE values for linear, quadratic, exponential growth and 
S-curve (Pearl-Reed logistic) are given in Table 1.

Table 1. MAPE values of selected trend models

\begin{tabular}{cc}
\hline Model & MAPE \\
\hline Linear & 185.78 \\
Quadratic & 65.06 \\
Exponential & 6.11 \\
S-curve & 6.00 \\
\hline
\end{tabular}

It is obvious that S-curve trend model consists of the minimum MAPE value and hence it was selected [5]. Then, mathematically, trend model is given by

$$
G_{t}=\frac{10^{7}}{\left[0.247476+371.7018\left(0.880110^{t}\right)\right]}
$$

where $0 \leq t<\infty$.

Time series plot and autocorrelation plot of the residuals of the trend model for government expenditure in Sri Lanka are depicted in following Figure 1 and Figure 2.

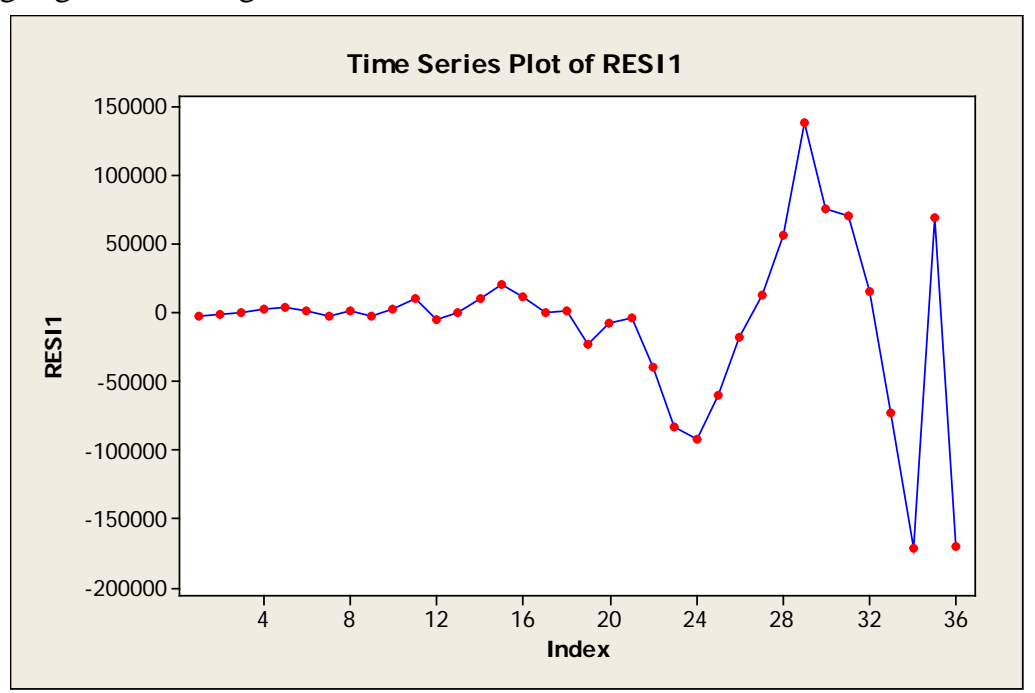

Figure 1. Time series plot of the residuals.

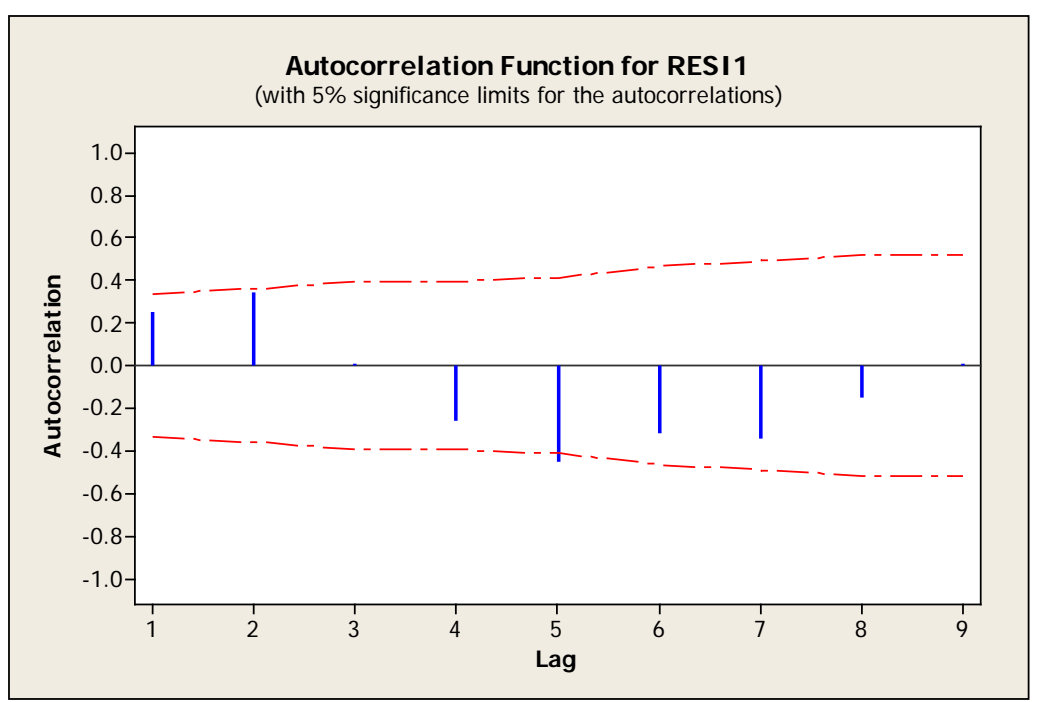

Figure 2. Autocorrelation plot of the residuals. 
Conclusively, Figure 1 and Figure 2 convince that residuals have no constant variation [7]. Hence, absolute value of the LOG transformation has to be applied for the data set of residuals. Then autocorrelation function (ACF) and partial autocorrelation function (PACF) for the transformed residuals are depicted in Figure 3 and Figure 4.

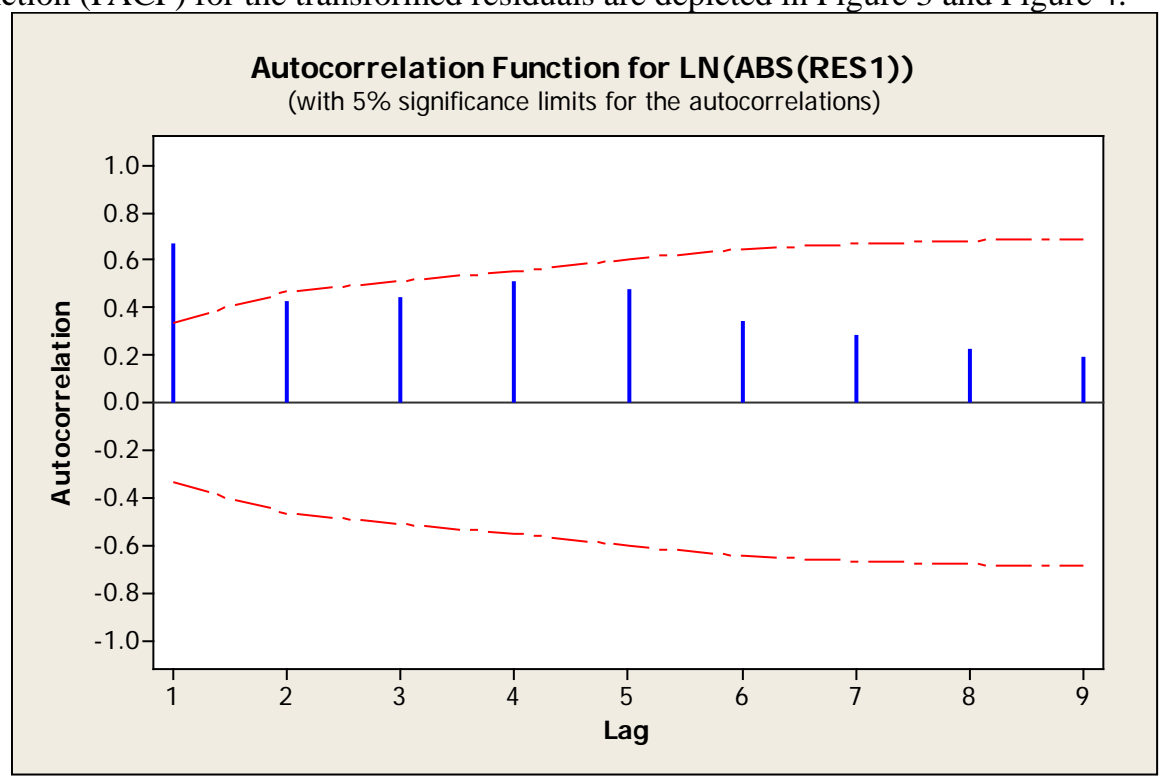

Figure 3. Autocorrelation plot of the transformed residuals.

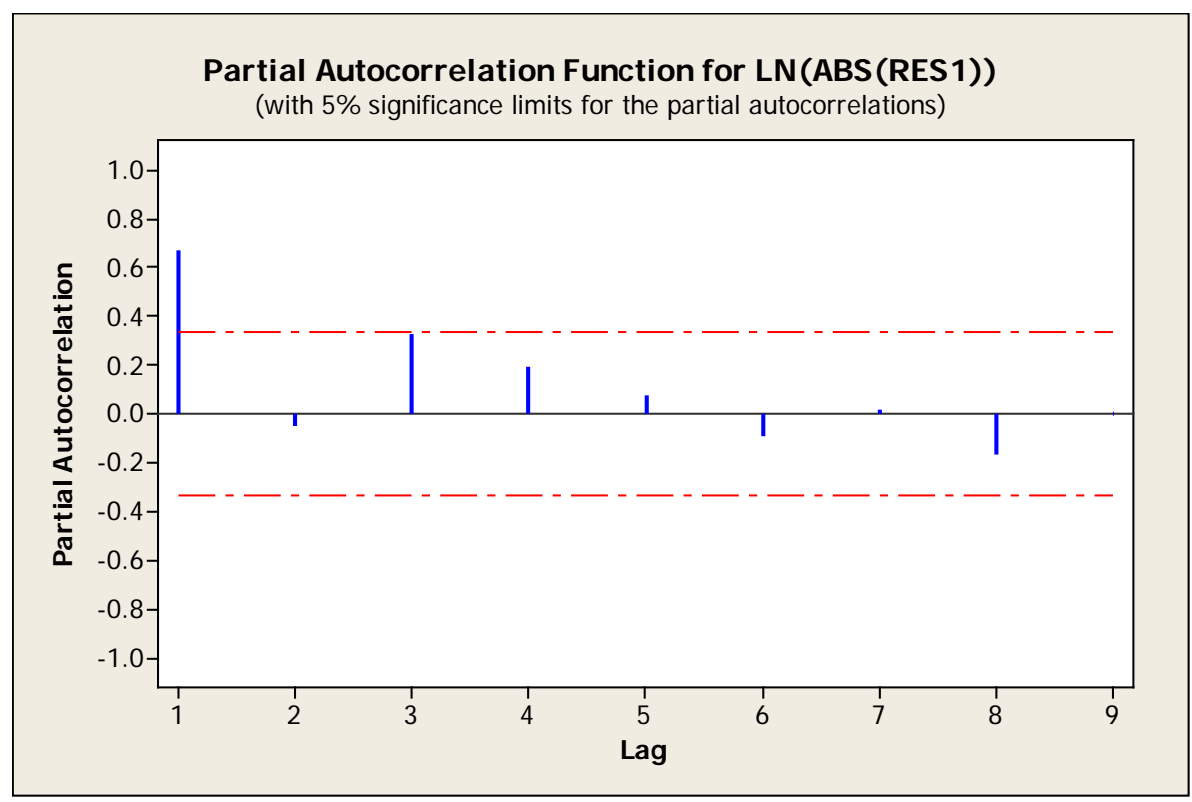

Figure 4. Partial autocorrelation plot of the transformed residuals.

According to the Figure 3 and Figure 4, ARIMA(1,0,2) can be tested [7] and corresponding MINITAB output is given in following Table 2.

Table 2. MINITAB output for ARIMA(1,0,2) model

\begin{tabular}{ccccc}
\hline Type & Coef. & SE Coef. & T & P \\
\hline AR1 & -0.8354 & 0.1539 & -5.43 & 0.000 \\
MA1 & -1.6713 & 0.0109 & -152.63 & 0.000 \\
MA2 & -0.7375 & 0.0631 & -11.68 & 0.000 \\
Constant & 17.0362 & 0.7805 & 21.83 & 0.000 \\
\hline
\end{tabular}


Apart from p-values of the output, in order to verify the model appropriately, run chart of residuals of ARIMA(1,0,2) model has to be tested as it is being used to test the randomness of the residuals. Figure 5 gives the run chart of the residuals.

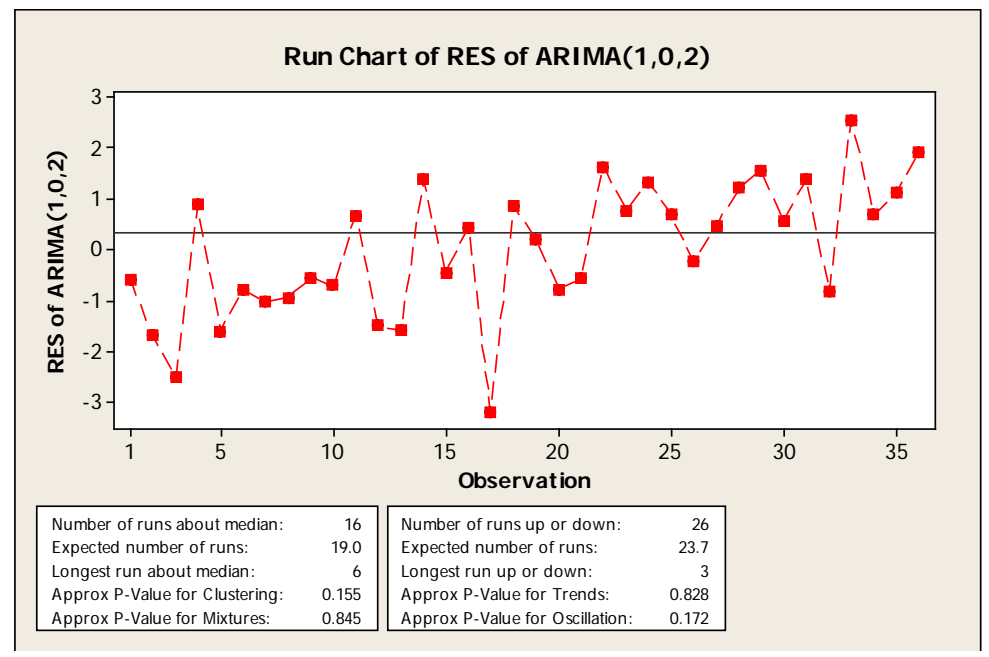

Figure 5. Run chart of residuals of $\operatorname{ARIMA}(1,0,2)$.

According to p-value (= 0.155) for clustering in Figure 5, we may conclude that residuals follow a random distribution. Normal probability plot of the residuals of ARIMA $(1,0,2)$ model is given in Figure 6. It is efficacious that plotted points are fairly close to the straight line drawn from lower left to upper right of the graph. Therefore, we may conclude that residuals are normally distributed [6].

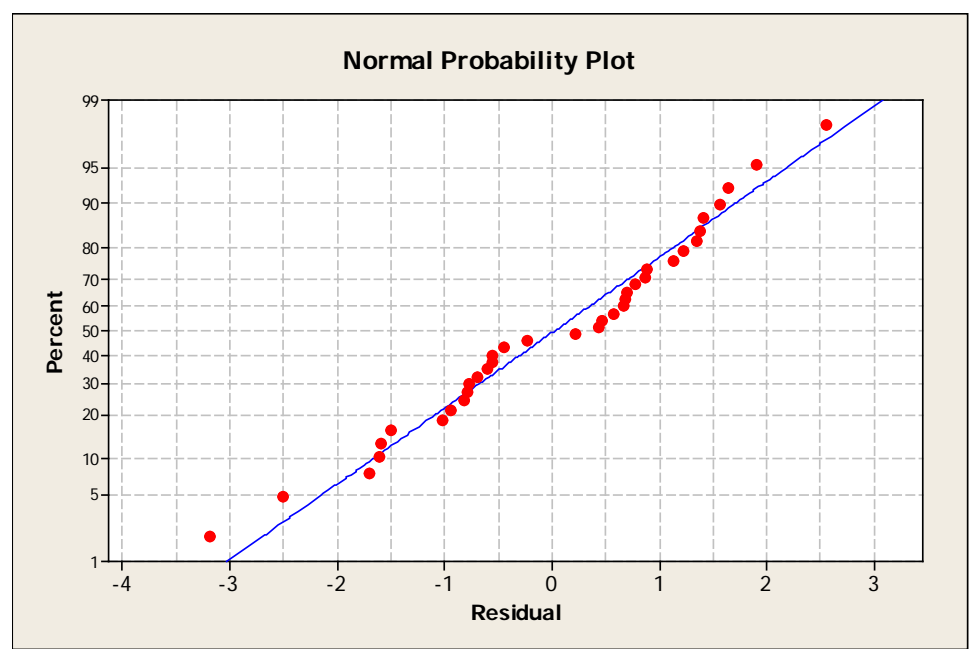

Figure 6. Normal probability plot of the residuals of ARIMA(1,0,2).

Hence, according to aforementioned results, final model is given by

$$
G_{t}=\frac{10^{7}}{\left[0.247476+371.7018\left(0.880110^{t}\right)\right]}+E_{t} ; \text { where }
$$

$E_{t}$ indicates the error term and $\ln \left|E_{t}\right|$ follows ARIMA $(1,0,2)$ for all $0 \leq t<\infty$.

Moreover, using the values in Table 02, final regression with ARIMA error model for government expenditure can be further written as

$$
G_{t}=\frac{10^{7}}{\left[0.247476+371.7018\left(0.880110^{t}\right)\right]}+E_{t} ; \text { where }
$$

$\left(\left|E_{t}\right|\right)\left(\left|E_{t-1}\right|^{0.8354}\right)=\exp \left(17.0362+e_{t}+1.6713 e_{t-1}+0.7375 e_{t-2}\right)$ for all $3 \leq t<\infty$. Here, $e_{t}$ denotes the residuals of $\operatorname{ARIMA}(1,0,2)$ model.

Hence, this non-linear model can easily be utilized to forecast the government expenditure in Sri Lanka and time series 
plot of actual (black colour) and forecasted (red colour) values of government expenditure in Sri Lanka are depicted in the following graph.

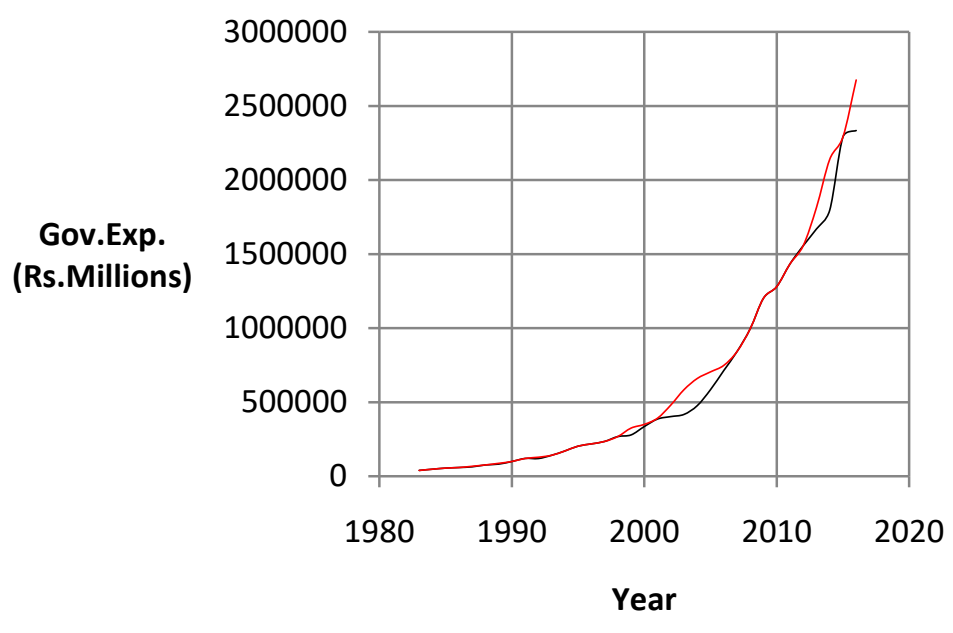

\section{Discussion and Conclusion}

1) In 2006 and 2016 government expenditure was abnormal due to unusual salary revisions in government sector. Therefore, time series model does not follow properly with actual values during those time periods as depicted in aforementioned graph.

2) The model is significant to make predictions if government expenditure varies accordingly exclusive of any instantaneous influences such as salary revisions by the government.

\section{References}

[1] Dwivedi, D. N. (2010). Macroeconomics theory and policy. $3^{\text {rd }}$ Edition, Tata McGraw Hill Education Private Limited, 600-603.

[2] Moessner, R. and William, A. A. (2010). Banking crises and the international monetary system in the Great Depression and now. https://www.bis.org/publ/work333.pdf.

[3] Lin, J. Y. Policy Responses to the Global Economic Crisis. https://openknowledge.worldbank.org/bitstream/handle/ 10986/4602/deor_11_3_29.pdf?sequence=1.

[4] Annual report. (2005). Central Bank of Sri Lanka, 66.

[5] Adhikari, R. and Agrawal, R. K. An Introductory Study on Time Series Modeling and Forecasting, Lambert Academic Publishing, 20-22, 43. https://www.researchgate.net/publication/235219651.

[6] Lind, D. A., Marchal, W. G., and Wathen, S. A. (2008). Statistical techniques in business and economics. $13^{\text {th }}$ Edition, Tata McGrow-Hill Publishing Company Limited, 532-533.

[7] Dettling, M. Applied Time Series Analysis, 51-53, 70, 88, 91-94. https://stat.ethz.ch/education/semesters/ss2014/ atsa/Scriptum_v140523.pdf.

[8] Annual report. (2017). Special Statistical Appendix, Central Bank of Sri Lanka. 